\title{
“Partiu estágio!" Relato de experiência de uma acadêmica de enfermagem
}

\author{
"Partiu estágio!" Experience report of a nursing student \\ "Partiu estágio!" Informe de experiencia de una académica de la enfermería
}

\section{Resumo}

Objetivo: Conhecer, a partir do relato de experiência de uma acadêmica do curso de Graduação em Enfermagem, as contribuições que o programa do governo do estado, "Partiu Estágio", proporcionou na sua formação acadêmica e identificar as lacunas na execução do referido programa. Métodos: Trata-se de um estudo qualitativo, descritivo, do tipo relato de experiência, que ocorreu em um hospital de grande porte de um município baiano, situado na região sudoeste do Estado, através do programa "Partiu Estágio". Resultados: As experiências vivenciadas durante o período de abril de 2018 a abril de 2019, assegurou a acadêmica uma formação diferenciada na realidade do Sistema Único de Saúde, dentre elas podemos elencar a Parceria Público-Privada. Conclusão: Essa experiência enriqueceu o arcabouço pessoal e profissional da mesma ao possibilitar superação de desafios, contornar situações adversas e tomada decisão, tendo como resultado o aprimoramento do senso crítico e do convívio interpessoal no ambiente de trabalho. Assim, ressalta-se a relevância da participação de acadêmicas (os) em programas de estágios extracurriculares para possibilitar uma formação crítico-reflexiva, priorizando os princípios e diretrizes do Sistema Único de Saúde; como também a necessidade em ampliar diálogos entre a gestão de programas de estágio do governo do estado, com as instituições de educação superior e instituições concedente do estágio.

Palavras-chave: Bolsa de estudo; Educação superior; Educação em enfermagem; Estudantes de enfermagem.

\begin{abstract}
Objective: Learn, from the experience report of an academic from the Bachelor's Degree in Nursing, the contributions that the state government program, "Partiu Estágio", provided in her academic training and identify the gaps in the execution of said program. Method: This is a qualitative, descriptive study, type report of the experience, that occurred in a hospital of a bahian city, through the "Partiu Estágio" program. Results: The experiences lived during the period from April 2018 to April 2019, ensured the academic a differentiated formation in the reality of the Unified Health System, among them we can list the Public-Private Partnership. Conclusion: This experience enriched her personal and professional formation by enabling her to overcome challenges, overcome adverse situations and make decisions, resulting in the improvement of critical sense and interpersonal interaction in the work environment. So, the relevance of the participation of academics in extracurricular internship programs is to enable critical-reflective formation, prioritizing the principles and guidelines of the Unified Health System, in addition to the need to expand dialogues between the management of internship programs of the state government, with the institutions of higher education and granting institutions of the internship.
\end{abstract}

Keywords: Fellowships and scholarships; Education higher; Education nursing; Students nursing.

\section{Resumen}

Objetivo: Conocer, a partir del relato de experiencia de una académica de la carrera de Licenciatura en Enfermería, los aportes que el programa de gobierno estatal, "Partiu Estágio", brindó en su formación académica e identificar las brechas 
en la ejecución de dicho programa. Método: Se trata de un estúdio cualitativo, descriptivo, tipo relato de experiencia, que se realizó en un hospital de un municipio de Bahía, a través del programa "Partiu Estágio". Resultados: Las experiencias vividas durante el período de abril de 2018 a abril de 2019, aseguraron a la académica una formación diferenciada en la realidad del Sistema Único de Salud, entre ellas podemos enumerar la Parcerias Público-Privada. Conclusión: Esta experiencia enriqueció su formación personal y profesional al permitirle superar retos, superar situaciones adversas y tomar decisiones, resultando en la mejora del sentido crítico y la interacción interpersonal en el entorno laboral. Así, se enfatiza la relevancia de la participación de académicos en programas de pasantías extracurriculares para posibilitar una formación crítico-reflexiva, priorizando los principios y lineamientos del Sistema Único de Salud, además de la necesidad de ampliar los diálogos entre la gestión de los programas de pasantías del gobierno estatal, con las instituciones de educación superior y las instituciones que otorgan pasantías.

Palabras clave: Beca; Educación superior; Educación en enfermería; Estudiantes de enfermería.

\section{Introdução}

O estágio como parte do processo de formação do educando, estabelece a interlocução entre o percurso acadêmico e o fazer profissional. Ao tempo que pode propiciar também o fortalecimento e a edificação do conhecimento teórico adquirido em sala de aula, somado a vivência do dia a dia laboral (Brasil, 2012) e com isso articular o processo de formação com e para o mundo do trabalho, o que para Gallotti e colaboradores (2021) se constitui como um instrumento de qualidade para a formação do futuro profissional.

Aproximando essa realidade ao campo da saúde, mais especificamente à área de enfermagem, podemos ratificar esse entendimento nas Diretrizes Curriculares Nacionais para os curso de graduação em enfermagem, instituídas a partir de 2001, as quais estabelecem que além dos conteúdos teóricos e práticos desenvolvidos ao longo da formação do educando, ficam os cursos obrigados a incluir no currículo o Estágio Supervisionado, a ser realizado em hospitais gerais e especializados, ambulatórios, rede básica de serviços de saúde e comunidade. Como também ressalta a necessidade da realização de atividades complementares que podem ser reconhecidas a partir de: Monitorias e Estágios, Programas de Iniciação Científica; Programas de Extensão; Estudos Complementares; Cursos realizados em outras áreas afins (Brasil, 2011).

Com isso, o estágio propicia a integração ensino-serviço, que pode ser compreendida como um trabalho coletivo e integrado de educandos e educadores dos cursos de graduação com os trabalhadores dos serviços de saúde, incluindo os gestores, tendo como objetivo à qualidade da formação profissional e o desenvolvimento/satisfação dos trabalhadores (Albuquerque, 2008). Ao tempo que essa imersão no mundo do trabalho propicia aos sujeitos envolvidos constante revisão das práticas profissionais, das práticas educacionais, favorecendo para uma atualização contínua, uma recusa à simplificação e à fragmentação do conhecimento (Shoji et al., 2021).

Ainda nesse processo de fortalecer a integração ensino-serviço encontramos na Política Nacional de Educação Permanente em Saúde (EPS), lançada pelo Ministério da Saúde (MS) por meio da Portaria 198, de fevereiro de 2004, e implementada pela Portaria $\mathrm{n}^{\circ} 1.996$ de 20 de agosto de 2007, que a formação e o desenvolvimento de trabalhadores na área da saúde, devem ocorrer numa perspectiva de considerar as especificidades e a superação das desigualdades regionais, a partir da problematização da realidade vivenciada que possa gerar aprendizagem significativa (Brasil, 2004).

Ratificamos esse entendimento em Ceccim e Ferla (2008) quando nos traz que o processo de aprendizagem no campo da prática deve exigir uma postura de problematização das experiências, observadas e discutidas, possibilitando ao estudante assumir o papel de sujeito no processo.

Algumas iniciativas comprometidas com a relevância social da universidade e dos processos de formação no campo da saúde têm, historicamente, visado articular universidade e serviços, buscam conectar os espaços de formação aos diferentes cenários da vida real de produção de cuidados à saúde (Almeida et al., 1999). Como exemplo podemos citar o "Partiu Estágio", uma iniciativa do governo do estado da Bahia. 
Research, Society and Development, v. 10, n. 5, e29510514978, 2021

(CC BY 4.0) | ISSN 2525-3409 | DOI: http://dx.doi.org/10.33448/rsd-v10i5.14978

O Programa Partiu Estágio é uma iniciativa da Secretaria da Saúde do Estado da Bahia (SESAB) e da Escola Estadual de Saúde Pública (EESP). Lançado em abril de 2017, amparado pela Lei Federal nº 11.788, de 25 de setembro de 2008 , e na Lei Estadual $\mathrm{n}^{\circ} 13.458$ de 10 de dezembro de 2015 e pelo Decreto Estadual n ${ }^{\circ} .17 .447$, de 22 de fevereiro de 2017, com o intuito de inserir, em campo de prática da rede estadual de saúde pública, estudantes do ensino superior das diversas áreas de conhecimento, incluindo a área da saúde e áreas afins, matriculados e que já tenham concluído $50 \%$ da carga horária do curso de graduação (Brasil, 2008; Bahia, 2017).

O estágio não obrigatório ou extracurricular pode ser entendido como aquele que não faz parte das atividades obrigatórias durante os cursos de graduação (Brasil, 2008). No entanto, propicia uma aproximação dos estudantes de diversas áreas do conhecimento à realidade do Sistema Único de Saúde (SUS), possibilitando-lhe aperfeiçoamento técnico-cultural, cientifico e de relacionamento humano e potencializando a preparação para o trabalho profissional do estagiário.

Nessa perspectiva, construímos as seguintes questões norteadoras para o nosso estudo: De que forma o programa "Partiu Estágio" do Governo Estadual contribui para a formação dos educandos dos cursos de graduação na área da saúde? Quais lacunas podem ser identificadas na sua execução?

Para responder às nossas questões objetivamos com este trabalho conhecer, a partir do relato de experiência de uma acadêmica do curso de Graduação em Enfermagem, as contribuições que o programa do governo do estado - "Partiu Estágio" proporcionou na sua formação acadêmica e identificar as lacunas na execução do referido programa.

\section{Metodologia}

Trata-se de um estudo de natureza qualitativa, do tipo relato de experiência, de cunho descritivo sobre a vivência de uma acadêmica do curso de graduação em Enfermagem de uma universidade pública, localizada no sudoeste baiano, situado à $365 \mathrm{~km}$ da capital do estado, que atuou como bolsista do estágio extracurricular da Secretaria de Saúde do Estado da Bahia/ Escola Estadual de Saúde Pública (SESAB/EESP) na rede estadual de saúde pública, denominado "Partiu Estagio". Os estudos qualitativos, na perspectiva de Minayo (2013), possibilitam desvelar as subjetividades que emergem da realidade social a qual estamos inseridos.

Assim, o estágio foi desenvolvido em um hospital de grande porte, assim classificado quanto ao número de leitos, de um município do interior da Bahia. Essa experiência ocorreu no período de abril de 2018 a abril de 2019, com carga horária de 20 horas semanais.

Fundada em 1947, a unidade hospitalar, campus onde a prática se desenvolveu, oferece serviços como: emergência médica de alta e média complexidade e atende nas especialidades de Clínica Médica, Pediatria, Cirurgia Geral, Psiquiatria, Neurocirurgia, Bucomaxilo, Traumato-Ortopedia, UTI adulto, Traumato-Ortopedia, além de Bioimagem (Bahia, 2014).

Essa unidade hospitalar conta com Parceria Público-Privada (PPP), na modalidade concessão administrativa, que conforme a lei 11.079, que dispõe sobre normas gerais para licitação e contratação de parcerias público-privada no âmbito da administração pública, é definida como contrato de prestação de serviços de que a Administração Pública seja a usuária direta ou indireta, ainda que envolva execução de obra ou fornecimento e instalação de bens (Brasil, 2004).

A chamada PPP pode ser em duas modalidades: uma na modalidade patrocinada, em que parte dos recursos vem do governo e outra parte vem dos usuários; e a outra denominada modalidade administrativa em que o pagamento realizado aos prestadores de serviço vem unicamente dos cofres públicos (Brasil, 2004). Importante ressaltar que essa parceria não envolve totalmente a unidade hospitalar que foi o cenário do estágio, apenas alguns setores.

Por meio da portaria $\mathrm{n}^{\circ}$ 2.616, de 12 de maio de 1998, que dispõe sobre a obrigatoriedade da manutenção, pelos hospitais do país, de Programa de Controle de Infecções Hospitalares (CCIH) (Brasil, 1998), somente em 2009 o referido hospital institui 
a Portaria 043/2009, de 29 de dezembro de 2009, publicada no DOE n ${ }^{\circ}$ 20.164 de 30/12/2009, constituindo assim a Comissão de Controle de Infecção Hospitalar. Essa comissão tem por finalidade desenvolver um conjunto de ações deliberadas e sistemáticas, com vistas à redução, máxima possível, da incidência e da gravidade das infecções hospitalares, e assim, melhorar a qualidade da assistência prestada (Bahia, 2009).

\section{Relato de Experiência}

No dia 20 de março de 2018 foi lançado o edital de chamamento dos primeiros comtemplados com as vagas de estágio. Sendo então estipulados cinco dias para que os acadêmicos comparecessem com os documentos comprobatórios (RG, comprovante de matrícula e a folha resumo do cadastro único) na instituição hospitalar que foram selecionados. Após a entrega dos documentos foi apresentado um termo de compromisso, no qual deveriam apresentar a disponibilidade de carga horaria e o compromisso em cumprir as exigências do Decreto $n^{\circ} 17.447 / 2017$, que estabelece as diretrizes para o programa de estágio aos cursos da educação superior no âmbito da administração direta, autárquica, funcional, sociedade de economia mista, e empresa pública do poder executivo estadual (Bahia, 2017).

A partir da assinatura do termo de compromisso deu-se prosseguimento na elaboração do termo/contrato que seguiu as exigências do referido decreto, e que só foi assinado no dia 04 de abril de 2018, quando ocorreu o primeiro contato com a representante legal da instituição que o estágio ocorreria. Foram oferecidas as boas vindas, informações gerais sobre normas e rotinas, bem como as regras da unidade hospitalar e de boa convivência.

Foi também apresentado o termo/contrato com base no Art. $7^{\circ}$ do Decreto supracitado que traz que no Termo de Compromisso de Estágio deve constar as seguintes informações: setor destinado a realização do estágio, carga horaria, valor da bolsa estágio, causa de rescisão ou desligamento, tempo de duração e obrigação das partes (Bahia, 2017). Esse termo/contrato foi assinado inicialmente pela acadêmica e posteriormente pelo professor orientador e demais responsáveis pela oficialização do programa.

Como consta no Art. $4^{\circ}$ desse Decreto o acompanhamento das atividades desenvolvidas pela acadêmica seria realizado pelo professor orientador, indicado pela instituição de ensino superior, e pelo supervisor de estágio, designado pelo órgão concedente do estágio (Bahia, 2017).

Ao procurar a instituição de ensino superior, a acadêmica foi informada que não havia uma comissão ou docente responsável para indicar. Ficando sob responsabilidade da mesma providenciar um docente lotado na instituição com disponibilidade para o referido acompanhamento. Ressalta-se que esse é o mesmo docente que deve assinar obrigatoriamente o termo/contrato. Essa foi uma tarefa árdua, pois o prazo para a entrega desse termo/contrato devidamente assinado era curto.

Nessa busca foi possível identificar que, em sua grande maioria, os docentes da instituição tinham outras demandas e não estavam disponíveis para assumir mais uma supervisão/acompanhamento. Identificamos também que algumas recusas foram devido ao não conhecimento do programa e/ou apoio da instituição de ensino.

Após essa busca e posterior assinatura do termo/contrato, o estágio teve início no dia 08 de abril de 2018, com as atividades iniciais previstas para serem desenvolvidas no setor de emergência do Hospital, mas devido a existência da PPP em parte dos atendimentos deste setor, não se sabia ao certo como seria a dinâmica e o funcionamento do mesmo, uma vez que a atuação da acadêmica na unidade alocada só poderia acontecer mediante a supervisão um(a) funcionário(a) efetivo da Secretaria de Saúde do Estado da Bahia (SESAB). Com isso, todos os acadêmicos que estariam designados para esse setor foram realocados para setores administrativos. Ficando a Comissão de Controle de Infecções Hospitalar (CCIH) como o campo destinado para a efetivação do estágio. 
Essa mudança causou, momentaneamente, um descontentamento, uma vez que fugiu as expectativas previamente construídas pela acadêmica em estagiar no setor de emergência, área de maior afinidade e que contemplava todo o seu planejamento prévio. No entanto, é importante ressaltar que essas mudanças acontecem no mundo do trabalho, e numa perspectiva freiriana todo trabalhador social deve ter compromisso com o seu fazer profissional independente das paixões/afinidades que por ventura possam envolver essas relações, uma vez que o que realmente importava eram as experiências que poderiam ser vivenciadas na realização do estágio.

Não obstante, ao observar a realidade das PPP nota-se que é algo presente, atualmente, na administração públicas, em todos os níveis de governo, e que traz impactos ao desenvolvimento do processo de trabalho, em especial no processo de trabalho em saúde, o que se pode caracterizar como uma precarização do trabalho. Essa inferência é possível porque em alguns estudos essas parcerias podem afetar a construção de vinculo, trazendo inseguranças quanto a permanência do trabalhador; pode também gerar conflitos nos regimes e condições de trabalho das equipes, deixando o trabalhador vulnerável às exigências gerenciais autoritárias e situações de exploração no trabalho, resultando em uma das faces da precarização do trabalho (Pereira, 2008; Sampaio et al., 2019; Sampaio \& Alves, 2018; 2019). Esse é um tema que merece atenção e um olhar cuidadoso, principalmente no tocante ao mundo do trabalho em saúde.

Ao adentrar ao novo setor, a CCIH, foi possível perceber a existência de ruídos no processo comunicacional dentro da instituição, uma vez que a enfermeira coordenadora do serviço ficou surpresa com a possibilidade da existência do estágio naquele setor, ao tempo que deixa claro não ter sido comunicada. Outro ponto que merece atenção nessa chagada se refere ao espaço físico do setor, que por ser reduzido, com aproximadamente $12 \mathrm{~m}^{2}$, era compartilhado com outros três setores que funcionavam no mesmo espaço físico, o que na nossa perspectiva pode comprometer as condições de trabalho e a ergonomia (Sampaio \& Alves, 2018; 2019), e que mais uma vez nos aproxima do tema sobre precarização do trabalho e ressalta a necessidade desse olhar cuidadoso sobre esta temática.

Segundo Saliba (2010, p.23) "a ergonomia cuida da adaptação das condições de trabalho às características psicofisiológicas dos trabalhadores, de modo a proporcionar o máximo de conforto, segurança e eficiência no desempenho". Fragilidade essa que poderia diminuir o bem-estar e a satisfação da equipe no local de trabalho (Sampaio \& Alves, 2018; 2019).

A equipe do CCIH era composta por uma enfermeira coordenadora, um infectologista, uma médica consultora, dois técnicos de enfermagem e uma auxiliar administrativa. Todos funcionários efetivos da SESAB, que muitas vezes precisavam realizar revezamento para desenvolverem o seu trabalho, além da dificuldade em realizar reuniões com todos os membros devido ao espaço físico, como também a dificuldades em tratar de questões éticas em um ambiente onde funcionavam outros setores. Com isso, ratifica-se a precarização das condições de trabalho e a mais uma vez a importância dessa temática.

Dentre as atividades desenvolvidas no setor pode-se citar: conhecimento do serviço e da equipe, investigações de possíveis infecções; avaliação de culturas realizadas nos pacientes; solicitação de culturas de controle de pacientes oriundo de outras unidades hospitalares; arquivamento e organização de documentos; busca ativa diária nos setores; visita aos pacientes internados na UTI; controle das dialises e da qualidade da água na unidade; controle de óbito; realização de capacitação para a equipe de enfermagem, com palestras sobre o funcionamento da CCIH, Normas e Rotinas da unidade de saúde, implementação da campanha "adorno zero"; elaboração de relatório mensal para registro das atividades desenvolvidas.

Em reunião com a coordenadora foi elaborado a escala de estágio a ser cumprida durante o período de cada mês, bem como as atividades, de competência do setor, que seria de responsabilidade da acadêmica, tais como: rondas diárias nos setores de circulação e acomodação de pacientes: verificação e contagem dos dispensadores de álcool gel e seu ideal funcionamento; enumeração de dialises realizadas e suas intercorrência , caso houvesse; busca de pacientes com culturas positivas, bem como a identificação em prontuário de casos de isolamentos de contato. 
Diante de todas as atividades desenvolvidas pelo setor, foi possibilitado a realização de grande parte delas. Uma experiência enriquecedora que facilitou o desempenho nas disciplinas subsequentes do curso. Ao tempo que se ressalta a importância e a gratidão em colaborar na produção, execução e avaliação das atividades de educação permanente realizadas na unidade de saúde durante o período de estágio. Essas atividades de educação permanente atendiam ao que Sampaio e colaboradores (2019) preconizam quando nos traz que essas atividades não devem se restringir à conhecimentos específicos sobre uma patologia, mas sim conhecimentos que possam impactar e favorecer a mudanças na realidade de trabalho.

Com 15 dias de estágio, já estava bem adaptados a rotina do setor, quando houve a mudança no fluxo da unidade hospitalar. A empresa parceira que efetivamente se instalava para assumir os setores da emergência, UTI, clinicas cirúrgicas, centro cirúrgico e clinica neurológica modificou a rotina desses setores, o que gerou insegurança no funcionamento dos mesmos uma vez que houve realocação de funcionários e até demissões. Nesse processo houve alguns entraves nas coletas e busca ativa, pois não existia um protocolo instalado para a fiscalização na ala de concessão administrativa.

Após reunião com os coordenadores e representantes da gestão, ficou instituído que os setores administrativos continuariam cobrindo todo o hospital como anteriormente, mas que um funcionário da PPP estaria presente para fazer essa interligação entre gestão pública e gestão privado.

As atividades continuaram a ser realizadas, no entanto alguns impactos foram identificados, entre eles é possível citar: uma discreta resistência por parte dos setores de responsabilidade da PPP; o acesso aos prontuários ficou prejudicado, bem como a aceitação de sugestões e dicas para a segurança do paciente e controle de infecções.

A conquista da confiança dos profissionais das equipes, levou tempo, mas com diálogos, ressaltando a importância da parceria CCIH-equipe para a unidade e para o serviço, visando a melhoria do atendimento e a segurança de todos, com o tempo criou-se uma relação de mutualismo.

No período do estágio a enfermeira até então responsável pela CCIH solicitou transferência para outra unidade hospitalar e o setor ficou, por um tempo, sem uma coordenação. Por consequência a supervisão direta ficou ausente. Fato esse que não prejudicou o andamento das atividades desenvolvidas, uma vez que a acadêmica já conhecia o setor e estava familiarizada com o fluxo interno. Sendo instituída uma enfermeira da PPP para assumir o cargo de coordenadora da CCIH, mas por não ser funcionária efetiva do estado não poderia assumir a supervisora direta e legal do estágio. Ficando com essa responsabilidade da supervisão a coordenadora do RH.

Durante esse período de transição a empresa de diagnóstico laboratorial foi substituída por outra sem o mesmo nível de complexidade e recurso. Esse fato dificultou o trabalho, visto que as culturas de controle eram a melhor forma para se prevenir e tratar corretamente uma infecção. Comunicações Internas e relatórios foram elaborados para enfatizar a insatisfação com a situação em que se encontrava o setor. Somente após três meses de muitas negociações o contrato com o antigo laboratório foi reestabelecido e o trabalho voltou a fluir melhor.

O espaço físico também sofreu alterações, após a criação de novas salas. A CCIH agora dividia espaço apenas com o Núcleo de Segurança do Paciente, o qual trabalhava em parceria. Com isso, percebe-se uma melhoria no que se refere ao espaço físico, com maior capacidade em acomodar os integrantes da equipe, o que possibilitou a realização de reuniões e discursões de casos com mais frequência. E com essas mudanças o estágio seguiu sem maiores intercorrências até o seu final.

\section{Considerações Finais}

O Programa de estágio extracurricular "Partiu Estagio" constituiu uma grande experiência para a formação técnicocientífica e certamente contribuirá futuramente enquanto profissional de saúde tanto no setor público quanto no privado. 
Research, Society and Development, v. 10, n. 5, e29510514978, 2021

(CC BY 4.0) | ISSN 2525-3409 | DOI: http://dx.doi.org/10.33448/rsd-v10i5.14978

A experiência neste estágio proporcionou, sobretudo, um aprendizado diferenciado, por não se tratar apenas de uma prática observacional, mas de ação e intervenção e com isso aprender a dinâmica do serviço. Essa experiência se configura como interação positiva, o que ressalta a importância na manutenção do programa de estágios para o aprimoramento da formação do futuro trabalhador, e com isso fortalecer a ideia de que os trabalhadores de saúde são sujeitos importantes e ativos no processo de educação/formação no sistema de saúde brasileiro.

Não se pode pensar que o estagiário está no serviço apenas para cumprir uma carga horária de atividades extras, mas sim, que ele pode contribuir muito para o desenvolvimento do trabalho no setor em que está inserido. Foi notório que a relação de troca de conhecimento ocorreu de forma natural e espontânea.

Desafios são esperados em qualquer atividade, e com o estágio não foi diferente, a falta, inicial, de um orientador e de supervisão direta, a não realização de avaliações sobre o desenvolvimento do estágio, bem como a atuação em uma unidade hospitalar com gestão mista tornou essa experiência desafiadora e enriquecedora como já mencionado em todo relato.

Que este trabalho suscite reflexões e estudos/pesquisas futuras sobre os temas da Educação Permanente em Saúde, Precarização do trabalho e suas multifaces, como também quanto ao processo de desenvolvimento e avaliação das atividades do estágio no campo e fora dele, principalmente quanto ao compromisso assumido por instituições de ensino superior, gestão em saúde e instituições concedentes no que se refere ao suporte adequado aos acadêmicos que realizam essas experiências extramuros.

\section{Referências}

Albuquerque, V. S (2008). A integração ensino-serviço no contexto dos processos de mudança na formação superior dos profissionais da saúde. Rev. bras. educ. med. 32(3), 356-362. http://www.scielo.br/scielo.php?script=sci_arttext\&pid=S0100-

Almeida, M, Feuerwerker, L. \& Llanos, M. (orgs) (1999). A educação dos profissionais de saúde na América Latina: teoria e prática de um movimento de mudança. Lugar Editorial, Ed. UEL.

Bahia (2009). Secretaria de Saúde do Estado da Bahia. DOE n. 20.164, de 30 de dezembro de 2009. Estabelece o Programa de Controle de Infecção Hospitalar, Salvador.

Bahia (2014). HGPV comemora 67 anos de funcionamento. 2014 abr. http://www.saude.ba.gov.br/2014/04/01/hgpv-comemora-67-anos-de-funcionamento.

Bahia (2017). Governo do Estado da Bahia. Decreto Estadual no 17.447 de 22 de fevereiro de 2017- Estabelece as diretrizes para o Programa de Estágio aos cursos da. Educação Superior no âmbito da Administração direta, autárquica, fundacional, sociedades de economia mista e empresas públicas do Poder Executivo

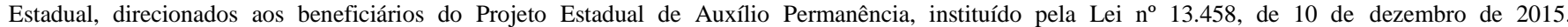
http://www.legislabahia.ba.gov.br/documentos/decreto-no-17447-de-22-de-fevereiro-de-2017

Brasil (1998). Ministério da Saúde. Portaria nº 2616, de 12 de maio de 1998 dispõe sobre a obrigatoriedade da manutenção pelos hospitais do país, de Programa de Controle de Infecções Hospitalares.

Brasil (2004). Casa Civil. Lei Federal n 11.079 , de 30 de dezembro de 2004. Institui normas gerais para licitação e contratação de parceria público-privada no âmbito da administração pública. Brasília.

Brasil (2004). Ministério da Saúde. Portaria GM/MS nº198, de 13 de Fevereiro de 2004. Institui a Política Nacional de Educação Permanente em Saúde. Ministério da Saúde.

Brasil (2008). Congresso Nacional. Lei Federal $\mathrm{n}^{\circ} 11.788$ de 25 de setembro de 2008 . Dispõe sobre o estágio de estudantes, http://www.planalto.gov.br/ccivil_03/_ato2007-2010/2008/lei/111788.htm

Brasil (2011). Conselho Nacional de Educação. Câmara de Educação Superior. Resolução CNE/CES n. 3 , de 7 de novembro de 2001. Institui Diretrizes Curriculares Nacionais do Curso de Graduação em Enfermagem. Brasília.

Brasil (2012). Ministério da Saúde. Secretaria de Atenção à Saúde. Política Nacional de Atenção Básica. Departamento de Atenção Básica. Ministério da Saúde.

Ceccim, R. B \& Ferla, A. A (2008). Educação permanente em saúde. In: Pereira IB, Lima JCF. Dicionário da educação profissional em saúde. (2a ed.), EPSJV.

Gallotti, F. C. M, Santos, L. E. R dos, Dias, V. G. A, Farias, Q. S. S, Martins, M. C. V, Góis, R. M. O de, Rosa, M. P. R. S, Lima, R. G, Trindade, L. S da \& Serafini, M. R. (2021). Formação do enfermeiro na perspectiva do cuidado integral e trabalho em equipe. Research, Society and Development, 10(1), e24110111724. https://rsdjournal.org/index.php/rsd/article/view/11724/10457

Minayo, M. C. S. O desafio do conhecimento: Pesquisa qualitativa em saúde. Hucitec, 2013. 
Research, Society and Development, v. 10, n. 5, e29510514978, 2021

(CC BY 4.0) | ISSN 2525-3409 | DOI: http://dx.doi.org/10.33448/rsd-v10i5.14978

Pereira, I. B., \& Lima, J. C. F. (2008). Dicionário da educação profissional em saúde. (2a ed.), EPSJV.

Saliba, T..M., \& Lanza, M. B. F (2018). Curso básico de segurança e higiene ocupacionall. (8a ed.), LTr.

Sampaio, D. M. N., \& Alves, A. E. S. (2018). As multifaces da precarização do trabalho e a enfermagem: uma revisão integrativa da literatura. In: Sampaio DMN (Org.). Memória, trabalho e saúde: construindo saberes. Editora CRV.

Sampaio, D. M. N., \& Alves, A. E. S. (2019). The world of work in the family health strategy from the nurses' perspective, International Journal of Development Research, 09, (04), 27566-27570. https://www.journalijdr.com/sites/default/files/issue-pdf/15546.pdf

Sampaio, D. M. N., Souza, M. N. R., Pires, V. M. M. M., \& Carvalho, C. A. P. (2019). Entendimento Dos Agentes Comunitários De Saúde Acerca Da Educação Permanente Em Saúde. Rev. Saúde.com, 14(4). https://doi.org/10.22481/rsc.v14i4.4244

Shoji, S., Avena, D. A., Carvalho, E. C., Soares, S. S. S., Varella, T. C. M. M. L., Farias, S. N. P., Andrade, K. B. S., Pereira, S. R. M., \& Souza, N. V. D. O. (2021). A formação de egressos de Enfermagem e seus estranhamentos no mundo do trabalho em saúde. Research, Society and Development, 10(1), e18110111558. https://rsdjournal.org/index.php/rsd/article/view/11558/10384 